\title{
Psychiatric genomics researchers' perspectives on best practices for returning results to individual participants
}

\author{
Kristin Kostick, $\mathrm{PhD}^{1}$, Stacey Pereira, $\mathrm{PhD}^{1}$, Cody Brannan, $\mathrm{MS}^{1}$, Laura Torgerson, MSc (i) ${ }^{1}$ and \\ Gabriel Lázaro-Muñoz, PhD JD ${ }^{1}$
}

Purpose: Large-scale array-based and sequencing studies have advanced our understanding of the genetic architecture of psychiatric disorders, but also increased the potential to generate an exponentially larger amount of clinically relevant findings. As genomic testing becomes more widespread in psychiatry research, urgency grows to establish best practices for offering return of results (RoR) to individuals at risk or diagnosed with a psychiatric disorder.

Methods: We interviewed an international sample $(n=39)$ of psychiatric genetics researchers to examine conceptualizations of "best practices" for RoR to individual research participants.

Results: While the vast majority of researchers do not offer RoR, most believed medically actionable findings (85\%) and clinically valid but non-medically actionable findings (54\%) should be offered. Researchers identified three main areas for improvement: interfacing with individual participants; interdisciplinary training, guidance, and integration; and quality planning and resource allocation for returning results.

Conclusion: There are significant gaps between researchers' visions for "best" versus "actual" RoR practices. While researchers call for participant-centered practices, including consent practices that consider any special needs of participants with psychiatric disorders, return of individually meaningful results, and effective follow-up and provisions for treatment, the current reality is that consent and RoR practices lack standardized and evidencebased norms.

Genetics in Medicine (2020) 22:345-352; https://doi.org/10.1038/s41436019-0642-7

Keywords: genetic; ELSI; neuroethics; ethics; qualitative

\section{INTRODUCTION}

Over the past decade, psychiatric genetics researchers have made remarkable progress in identifying genomic correlates of psychiatric disorders. ${ }^{1}$ Most of these findings emerged through large-scale genome-wide association studies that use highly multiplexed single-nucleotide polymorphism (SNP) arrays to collect genomic data; however, the use of genome and exome sequencing is also on the rise in psychiatric genetics research. ${ }^{1-4}$ Large-scale array-based and sequencing studies have increased our understanding of the genetic architecture of psychiatric disorders. However, these genetic testing tools potentially generate an exponentially larger amount of clinically relevant primary, secondary, and incidental findings compared with single-gene testing or candidate-gene studies. ${ }^{5}$ Genomic researchers from different fields of medicine have struggled with how to manage these findings. ${ }^{6-9}$

This issue is somewhat novel for psychiatric genetics research because, until recently, few clinically relevant findings were generated in this context, and the use of genome and exome sequencing was not as common as in other medical research fields. In addition, there are aspects of psychiatric genetics research that make scalable and responsible return of results particularly challenging. ${ }^{10}$ The large samples necessary to detect small effect sizes of genomic loci that contribute to the overall risk for these disorders raise the cost of returning individual results in these studies. ${ }^{1,3}$ Further, the polygenic nature of psychiatric disorders and the important role of environmental factors in psychiatry may complicate the interpretation of research findings. This can also complicate the process of returning findings in ways that clearly and meaningfully convey to participants the potential implications and limitations of results. Additionally, the high prevalence of mental health stigma can potentially lead to genomic-based discrimination toward participants and self-stigma for those identified with risk variants. ${ }^{11}$ Some theorize that psychiatric genetic information may increase stigma via genetic essentialism bias, while others suspect it could reduce stigma by suggesting the patient is not at fault for the condition. ${ }^{12-15}$

Finally, unlike return of results in other medical research, a higher proportion of participants in psychiatric genetics studies is expected to be at risk or diagnosed with a psychiatric disorder. This heightened risk could make them more likely to be

${ }^{1}$ Center for Medical Ethics \& Health Policy, Baylor College of Medicine, Houston, TX, USA. Correspondence: Gabriel Lázaro-Muñoz (glazaro@bcm.edu) 
emotionally affected by the return of pathogenic findings. To responsibly manage return of results in this growing field of genomics research, it is critical to address the unique and accentuated challenges in psychiatric genomics research.

Despite increasing consensus that some clinically relevant findings should be offered to individual participants in genomics research, ${ }^{6,8,16-18}$ including psychiatric genetics, ${ }^{10,19-21}$ there is little empirical data about how to ideally manage return of results (RoR) in the psychiatric genetics research context. ${ }^{22,23}$ Most research on RoR in genetics research has focused on whether results should be offered, and the perceived risks and benefits of returning results, ${ }^{7-9,18,24,25}$ along with which types of results (e.g., medically actionable, clinically valid but not actionable) are justifiable and recommended to return. ${ }^{5,7,18,20}$ From this research, we know that participants and other nonresearcher stakeholders support RoR from genomic and psychiatric genomic research. ${ }^{18,20,26}$ A majority (over 90\%) of researchers generally support offering to return some findings to individual research participants. ${ }^{7,18}$ Researchers in psychiatric genetics also appear to support offering RoR. ${ }^{10,20}$ They are similarly motivated to return results, but also voice significant uncertainty about how to weigh a participant's "right to know" against researchers' desire to protect individuals with a psychiatric disorder from receiving results that could impart psychosocial harms, such as stress, anxiety, increased stigma, and discrimination. ${ }^{7,10}$ While these studies have opened a broader dialogue about whether results should be offered and why, only a few empirical studies to date have specifically addressed which results should be offered and how results should be returned in psychiatric genetics research. ${ }^{19-21,27}$ No empirical study has examined these issue from the perspective of psychiatric genomics researchers who are key stakeholders in implementing plans for returning results.

As more and more psychiatric genomics researchers engage in return of results and variability increases with respect to how researchers decide to return results, the urgency of addressing procedural concerns grows. There is a need for greater clarity on how to approach the return of results in psychiatric genetics research, taking into account the particular ethical and logistical considerations of returning results to individuals who may have an existing disorder or significant risk for developing a psychiatric disorder. ${ }^{5,10}$ Here, we empirically examine conceptualizations of "best practices" for returning results to this population of research participants, drawn from qualitative interviews with international researchers in psychiatric genetics. In our discussion, we address challenges and potential solutions for moving toward a set of guidelines for more ethically justified and systematic return of results in psychiatric genetics research.

\section{MATERIALS AND METHODS}

Using semistructured, open-ended interviews, participants $(n=39)$ were asked their perspectives on returning individual results in psychiatric research. We developed our interview guide (see Supplement A in the Appendix) based on existing literature and gaps therein, as well as discussions with colleagues in the field. Five pilot interviews were then conducted with researchers to test the fit of our interview guide to our research questions, and only minimal changes were subsequently made. Interviews lasted an average of 47 minutes and were conducted in English or Spanish. The open-ended interview format was chosen to capture researchers' attitudes, values, and beliefs about current versus ideal practices, along with the challenges of and barriers to responsibly returning results to individuals. The study was approved by the Baylor College of Medicine Institutional Review Board.

\section{Participant sampling}

Participants were selected based on current involvement in psychiatric genetics research, with a preference for established researchers from a wide-range of regions and specialties performing different types of genetic testing. ${ }^{10}$ We recruited participants via email through their membership in the International Society of Psychiatric Genetics (ISPG) ${ }^{10}$ and at the 25th World Congress of Psychiatric Genetics (WCPG) in Orlando, Florida in October 2017. Interviews were conducted by three members of the research team, including the principal investigator (PI) and two anthropologists (K.K. and S.P.) trained in qualitative interviewing. Interviews took place via phone/ Skype or in person at WCPG. We continued to conduct interviews until saturation of themes was reached. ${ }^{28}$

\section{Analysis}

Interviews were audio-recorded, transcribed, and analyzed using MAXQDA software. ${ }^{29}$ We developed our codebook collaboratively across three members of the research team and completed three rounds of coding before reaching consensus, which was achieved through iterative, collaborative discussions about any discrepancies in code attributions. Of the 21 codes included, 9 were used to specifically search for themes related to researchers' perspectives toward best practices for returning individual research results in psychiatric genetics. Thematic content analysis ${ }^{30}$ was used to identify and refine themes, involving a systematic process of abstracting content of quotes into themes and assessing theme prevalence across respondents. Reported percentages represent the number of participants who expressed a certain viewpoint. Therefore, to say that $13 \%$ of respondents advocated returning all results to participants does not imply that $87 \%$ voiced the opposite view. While this could be true, it could also be that they chose not to discuss it, as interviews were open-ended and largely participant-led to allow participants to address topics salient to them and within their realm of comfort to discuss.

\section{Best practices for RoR}

\section{RESULTS}

\section{Which results should be offered and why}

Respondents included 39 researchers in psychiatric genetics, spanning 17 countries, and focusing on a range of psychiatric disorders (Table 1; see also Kostick et al. ${ }^{10}$ for current return 
Table 1 Demographics of participants $(n=39)$

\begin{tabular}{|c|c|}
\hline Gender & $n(\%)$ \\
\hline Female & $14(36 \%)$ \\
\hline Male & $25(64 \%)$ \\
\hline \multicolumn{2}{|l|}{ Principal investigator status } \\
\hline Yes & $37(95 \%)$ \\
\hline No & $2(5 \%)$ \\
\hline \multicolumn{2}{|l|}{ Country } \\
\hline United States & $16(41 \%)$ \\
\hline Australia & $3(8 \%)$ \\
\hline Canada & $3(8 \%)$ \\
\hline Denmark & $3(8 \%)$ \\
\hline Germany & $3(8 \%)$ \\
\hline Asia & $2(5 \%)$ \\
\hline Other European countries & $4(10 \%)$ \\
\hline $\begin{array}{l}\text { North, Central, and South America, excluding United States } \\
\text { and Canada }\end{array}$ & $5(12 \%)$ \\
\hline \multicolumn{2}{|l|}{ Educational background } \\
\hline MD only & $16(41 \%)$ \\
\hline $\mathrm{MD}$ and $\mathrm{PhD}$ & $6(15 \%)$ \\
\hline $\mathrm{PhD}$ only & $16(41 \%)$ \\
\hline Other & $1(3 \%)$ \\
\hline \multicolumn{2}{|l|}{ Years of experience in psychiatric genetics research } \\
\hline$\leq 5$ years & $5(13 \%)$ \\
\hline $6-10$ years & $8(21 \%)$ \\
\hline $11-15$ years & $6(15 \%)$ \\
\hline $16-20$ years & $10(26 \%)$ \\
\hline $21+$ years & $10(26 \%)$ \\
\hline \multicolumn{2}{|l|}{ Types of genome testing conducted } \\
\hline SNP arrays only & $18(46 \%)$ \\
\hline GS/ES only & $9(23 \%)$ \\
\hline SNP arrays and GS/ES & $9(23 \%)$ \\
\hline No genetic testing ${ }^{a}$ & $2(5 \%)$ \\
\hline SNP arrays and Sanger sequencing & $1(3 \%)$ \\
\hline \multicolumn{2}{|l|}{ Research focus by psychiatric disorder } \\
\hline Schizophrenia & $20(51 \%)$ \\
\hline Bipolar disorder & $13(33 \%)$ \\
\hline Depression and postpartum depression & $8(21 \%)$ \\
\hline Autism & $6(15 \%)$ \\
\hline Alcohol abuse and addiction & $5(13 \%)$ \\
\hline Obsessive-compulsive disorder (OCD) & $3(8 \%)$ \\
\hline Intellectual disabilities & $2(5 \%)$ \\
\hline Eating disorders & $2(5 \%)$ \\
\hline Dementia and Alzheimer disease & $2(5 \%)$ \\
\hline No specific disorder (meaning all psychiatric disorders) & $2(5 \%)$ \\
\hline Others & $8(21 \%)$ \\
\hline \multicolumn{2}{|c|}{$\begin{array}{l}\text { ES exome sequencing, GS genome sequencing, SNP single-nucleotide polymorphism } \\
\text { aThese researchers conduct studies on genetic counseling and other issues related to } \\
\text { psychiatric genetics but do not perform genetic testing. } \\
\text { bMany researchers study different psychiatric disorders, thus the numbers under psy } \\
\text { chiatric disorder focus are not mutually exclusive. }\end{array}$} \\
\hline
\end{tabular}

of results practices among our sample). As we did not see any patterned (thematic) differences based on provenance (country), nor between clinicians and researchers (many of who were clinician-researchers), we report findings for the whole sample. Figure 1 presents researchers' perspectives toward which types of results should be offered. We defined for participants a "medically actionable finding" as "a genomic

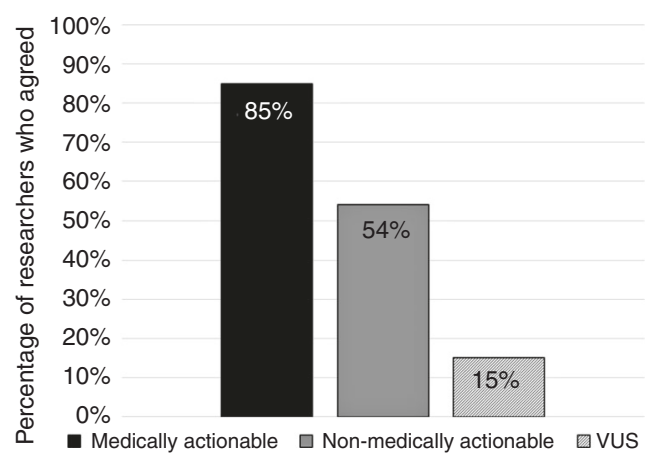

Fig. 1 Which genomic findings should be offered? Researchers' support for offering to return medically actionable, non-medically actionable, and variants of uncertain significance from psychiatric genetics research. VUS variant of uncertain significance.

result that indicates risk for a health condition for which there is some medical intervention available that can help decrease risk of illness or help manage symptoms." We developed this definition based on a review of how the term is discussed in the literature and on discussions with expert researchers in genomics. ${ }^{5}$

We previously reported that most of these researchers are not offering RoR. ${ }^{10}$ However, most researchers supported offering to return medically actionable (85\%) findings. Notably, $54 \%$ of researchers stated that non-medically actionable findings should be offered to participants. When we asked about non-medically actionable findings, we used examples such as risk for Alzheimer and Huntington disease. A majority (64\%) said that actionability is ideal but not necessary for medical relevance in psychiatric genetics, and that medical relevance is a larger category that contains rather than is separate from medical actionability. When asked whether variants of uncertain significance (VUS) potentially related to a participant's psychiatric disorder should be offered, giving the example of a "VUS found in genomic loci known to be associated with schizophrenia," only $15 \%$ agreed.

Table 2 presents researchers' rationale for supporting the offer of different types of results. Reasons for offering medically actionable results invoked issues related to duty to warn, improving participants' quality of life, and facilitating opportunities for early intervention. Reasons against cited conflation of research and clinical care, potential for burdening patients with unexpected information, and burdening researchers who lack appropriate resources to support searching for and returning results. Those who supported offering non-medically actionable results cited a participant's "right to know," and to monitor and prepare, while those against argued that the information can be a burden in the absence of any direct impacts on treatment or preventability, as well as the possibility for confusing participants with information lacking any clear benefit to them. Proponents of offering VUS said that results should be offered because they may be associated with other treatable conditions and are routinely being offered anyway, while critics said VUS are not meaningful for participants and could cause undue worry or 
Table 2 Researchers' rationale for which results should be returned

\begin{tabular}{|c|c|}
\hline \multicolumn{2}{|c|}{ Actionable results } \\
\hline \multirow[t]{2}{*}{ For: $(85 \%)^{a}$} & $\begin{array}{l}\text { When you can do something about it, I think it's a duty, } \\
\text { it's a medical duty, it's a medical diligence, to do } \\
\text { something about it. }\end{array}$ \\
\hline & $\begin{array}{l}\text { Because I think it's part of the mission of trying to improve } \\
\text { the quality of life of patients. If [it's] medically actionable, } \\
\text { yes, I think we have an obligation to return that. }\end{array}$ \\
\hline \multirow[t]{2}{*}{ Against: (10\%) } & $\begin{array}{l}\text { We're not in that business. We didn't promise to do that. } \\
\text { The subjects are not expecting it. We have no resources to } \\
\text { support this. We have no resources to provide } \\
\text { interpretation. And we're not looking for these things. }\end{array}$ \\
\hline & $\begin{array}{l}\text { Research and clinical care should be kept completely } \\
\text { separate, that researchers might be overly burdened by } \\
\text { having to report, and that participants may be harmed by } \\
\text { receiving information that they didn't really anticipate } \\
\text { when they signed up for the study. }\end{array}$ \\
\hline \multicolumn{2}{|c|}{ Non-medically actionable results } \\
\hline \multirow[t]{2}{*}{ For: (54\%) } & $\begin{array}{l}\text { Participants (and sometimes families) have a "right to } \\
\text { know," and should be given the chance to prepare. }\end{array}$ \\
\hline & $\begin{array}{l}\text { Can allow for behavioral change, family planning, end-of- } \\
\text { life care, changes in lifestyle including diet and exercise, } \\
\text { cognitive enhancement therapies, experimenting with } \\
\text { pharmacogenetics or other interventions, and especially } \\
\text { increased surveillance/monitoring of health status. }\end{array}$ \\
\hline \multirow[t]{2}{*}{ Against: (15\%) } & $\begin{array}{l}\text { If we don't have the genetic testing at this point that's } \\
\text { going to change the immediate care of that patient, there } \\
\text { is no rationale for doing it. }\end{array}$ \\
\hline & $\begin{array}{l}\text { The question is, "Is it good or is it bad for the individual?" } \\
\text { If it's something that can be treated and important to } \\
\text { recognize as early as possible, then it's good. But if you } \\
\text { can't do anything about it, it's a problem. The information } \\
\text { is a burden. }\end{array}$ \\
\hline \multicolumn{2}{|c|}{ Variants of uncertain significance (VUS) } \\
\hline \multirow[t]{2}{*}{ For: $(15 \%)$} & Some VUS are already being routinely returned anyway. \\
\hline & They may be associated with other treatable conditions. \\
\hline \multirow[t]{2}{*}{ Against: $(33 \%)$} & $\begin{array}{l}\text { Considered to have "no meaning" yet for individual } \\
\text { participants. }\end{array}$ \\
\hline & $\begin{array}{l}\text { Could potentially cause undue concern or worry among } \\
\text { participants, particularly those with existing psychiatric } \\
\text { conditions that predispose them to stress, anxiety, or } \\
\text { depression. }\end{array}$ \\
\hline
\end{tabular}

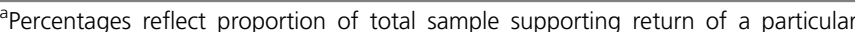
result type, and may not add up to $100 \%$ due to omission in this table of participants reporting who did not provide a clear response in favor or against offering these results.

stress. Almost half of all respondents (49\%) stated that there should be certain contingencies (e.g., should involve input from clinicians, should be confirmed by a clinically certified lab, etc.) for returning results of any kind, while only $13 \%$ advocated returning all results to participants.

\section{Main aspects of best practices for RoR}

Our respondents identified three areas of improvement for achieving best practices for RoR specific to psychiatric genetics: (1) interfacing with individual participants; (2) interdisciplinary training, guidance, and integration; and (3) quality planning and resource allocation for returning results. Below we present their suggestions for each, accompanied by an examination of current practices and existing challenges to achieving best practices for returning results in psychiatric genetics research, as perceived by active researchers in the field.

Theme 1: Interfacing with individual participants. Consent practices

Nearly half of respondents (46\%) said that consent practices regarding return of results should be improved. About a third (31\%) of respondents explicitly opposed paternalistic approaches to consent for RoR (e.g., returning results because clinicians feel patients "should know," despite participants' stated preferences to not know), and $21 \%$ said that participants, not surrogates, should choose whether they want to receive or opt out of certain types of information. Notably, $27 \%$ nevertheless believed that specialized consent practices for RoR should be created specifically for individuals with a psychiatric disorder. For example, one researcher commented, "There has to be extra care given to the vulnerabilities of the psychiatric population and the additional barriers to support and follow-up care that they may face." About a quarter (21\%) said that consent should involve pretest counseling and "due diligence" by research staff trained in RoR (e.g., genetic counselors) or partnering clinicians to identify individuals who may have compromised decision-making capacity related to a psychiatric condition. A rationale provided by some researchers (15\%) was that ordinary consent procedures may not account for the fact that some patients with psychiatric disorders might not understand what they are consenting to or might change their minds later. One researcher asked, "How capable are people that are really disabled or severely affected to give consent?"

Follow-up and treatment

Respondents (36\%) discussed challenges with follow-up to conduct RoR similar to those in other areas of genomics research, namely challenges related to tracking participants while also maintaining confidentiality (10\%); loss of contact (8\%); feasibility in the context of big sample sizes (8\%); delays between consent, analysis, and RoR (8\%); and difficulties keeping pace with the rate of scientific discovery (5\%). One follow-up issue cited as more unique to psychiatric genetics is the need to incorporate opportunities for treatment for individuals whose results reveal or confirm substantive risk for a psychiatric disorder (26\%). One respondent stated, "If patients [are] given results that are potentially concerning [and] cause potential exacerbation of illness, [they] need to be given within a context of supportive counseling." Researchers who return results may feel obligated to also provide access to treatment, especially for patient participant groups (e.g., participants with schizophrenia) who are traditionally underserved, uninsured, and/or without access to health care (5\%). A researcher pointed out that " $[\mathrm{p}]$ sychiatric patients tend to be more isolated, more cut off from family support, and have less access to medical care in general, so there's a 
higher burden on the researcher to make sure the participant can get some help." However, a number of respondents (26\%) viewed this as a "conflation" of research and clinical care and felt it could inhibit some researchers from returning results if it obligates them to refer participants for treatment. One researcher pointed out that "[when] research and clinical care [are not] kept completely separate, researchers might be overly burdened by having to report." However, another respondent suggested that a reluctance to return results to avoid dealing with treatment issues could constitute patient neglect.

Furthermore, even researchers willing to help route patients into care reported feeling challenged by a "fragmented" health-care system where researchers lack collaboration with psychiatrists and psychologists and/or are uninvolved in the health-care system directly. Some researchers (8\%) felt that results should be delivered directly to a clinician familiar with the participant, who can then relay results in ways sensitive to a participant's specific mental health needs. One respondent said, "[we] probably need to have some possibility for genomic counseling, or somebody there to help explain and put things in context."

Theme 2: Interdisciplinary training, guidance, and integration. Training and guidance for RoR

A number of psychiatric genetics researchers (31\%) reported feeling a lack of confidence in their knowledge and skills to determine whether and how to return results, or how to integrate RoR into psychiatric genetics research in practice, and preferred to rely on medical geneticists, counselors, and/or psychiatrists to return results instead. One researcher said, "We're not qualified to do this." A quarter (25\%) explicitly called for greater clarity in psychiatric genetics about what results should be returned (e.g., using which criteria or penetrance thresholds to evaluate significance) and greater procedural clarity about how to conduct RoR (e.g., in a "discussion format," using visual aids, etc.). "When it gets down to the minutiae of how and what to return," said one respondent, "I don't have a strong place to stand." Some (21\%) characterized the field of RoR in psychiatric genetics as offering "a complete lack of guidance," with some calling for templates for how to summarize results and give clinical recommendations, more empirical studies examining impacts of RoR on participants and families, and opportunities to partner with existing task forces within psychiatric organizations to consult for best practices of illness-specific RoR.

\section{Interdisciplinary integration and collaboration}

Nearly a third of respondents (28\%) called for greater integration of clinical and genetic information in cases where results have implications for clinical decision-making. One researcher observed a lack of professionals working in both psychiatry and genetics. Specifically, one researcher said, "You have people who are doing genetics or they're psychiatrists. There are still not many people at the interface of the two fields." About half of respondents (51\%) commented that "front line" physicians, clinicians, and even psychiatrists lack knowledge and training about the role of genetics in psychiatry, often viewing it as too complicated or irrelevant, thereby limiting their ability to communicate relevance and implications to participants/ patients. Over a third (36\%) likewise indicated a lack of "appropriate, trained personnel" knowledgeable in psychiatric genetics willing to take responsibility for RoR, with sufficient expertise to counsel, clearly explain consequences of results, and make results (especially risk) understandable and meaningful for a psychiatric population. A researcher commented about RoR, "Some aspects are so complex that I do not always know how I should handle it." Others (26\%) specifically called for genetic counselors to be integrated at every stage of research, from consent to RoR, ideally working onsite with researchers to help communicate risk, make meaning of results, and to put things "in context" for participants. Counselors would ideally form part of a larger well-trained team, offered a number of respondents (13\%), that would also include psychologists/psychiatrists, and clinical geneticists able to gauge the relevance or actionability of results for an individuals' treatment, as well as what to expect (e.g., emotional and behavioral responses) when returning results to individuals with specific psychiatric conditions.

Respondents (18\%) pointed out that even where researchers, clinicians, and other professionals are willing to collaborate, they must address potential challenges related to institution- or country-level regulations that inhibit or require collaboration with third parties (e.g., other labs, databases, or professionals from other clinical settings). One researcher commented that institutional review boards sometimes act as a "firewall" between research and clinical translation.

Theme 3: Quality planning, funding, and resource allocation for RoR. Strategic planning for RoR

Some respondents (21\%) blamed inconsistent RoR practices in psychiatric genetics on a lack of planning and foresight, as well as a culture where RoR is "just not the thing" (13\%). Research in psychiatric genetics was perceived by some researchers as "not designed to return results" or look for actionability. Researchers (10\%) said they lack a formalized process for planning and design of RoR, including methods for conducting "due diligence" with individual participants to ensure understanding (e.g., via early participant consultation with genetic counselors), and utilization of guidelines to adapt on a case-by-case basis. "There are no return of results standards. There's very little out there about what to do with psychiatric [genomic] findings," said one researcher. Others (8\%) pointed out a need for more well-considered formats for results delivery tailored to specific psychiatric populations, to potentially include sit-down discussions, invitations to participate in RoR via email, phone, Internet, or other scalable and preferred mediums.

Quality-controlled procedures to prevent harm to participants

A primary goal of systematizing RoR procedures, said over a quarter of respondents (26\%), is to reduce harm (e.g., negative emotional or behavioral reactions, changes in treatment adherence) to individual participants through quality-controlled 
RoR procedures. One researcher said, "We need better technologies, better methodology, more time, and more careful planning and designing of studies [in order] to properly return results." About half (49\%) of respondents recognized a need to institute procedures that effectively predict and prevent negative emotional and behavioral reactions from individuals receiving results. A number of respondents (10\%) pointed out that the level of "due diligence" required to predict variability in and prevent negative reactions among individuals with specific psychiatric conditions may be greater than for nonpsychiatric populations or controls, thus requiring significantly more funding for strategic RoR than in other fields of genetic research. Consistently, about half (54\%) of respondents said that psychiatric genetics currently lacks sufficient funding and resources for RoR, including for "contacting participants, letting them know [results] and providing relevant counseling." Some (10\%) suggested that research budgets should be (but usually are not) written to incorporate costs of RoR "to reflect what we value," and that funding agencies should formally recognize and prioritize allocation policies to incorporate RoR in psychiatric genetics. Researchers in turn should devise scalable strategies for RoR, proposed others (5\%), including the use of not only genetic counselors to deliver RoR but also more scalable alternatives, such as physicians with ethics or genetic backgrounds who could serve dual roles. Another researcher said about genetic counseling, "It's not scalable cost-wise, the idea of 'I'm going to have this long genetic counseling and...talk to you about your feelings.' It has to be through your phone, through the Internet, through [another] way of reaching out."

\section{DISCUSSION}

The ideals identified by researchers in psychiatric genetics emphasize a participant-centered approach to return of results, highlighting the importance of improved consent practices; the need to return results that are individually meaningful, even if not medically actionable; and the need to ensure that participants can be reached following participation and offered opportunities for treatment when necessary. The finding that $54 \%$ of researchers believe non-medically actionable results should be offered was striking for various reasons. The ethical arguments for RoR in the research setting, and many of the guidelines regarding which findings should be offered in both the clinical and research settings, have stressed the importance of medical actionability. ${ }^{5,8,9,16,17,27}$ Some have argued for the return of non-medically actionable findings, though not as commonly as for returning medically actionable findings. ${ }^{5,6}$ For example, Jarvik et al. $^{6}$ reasoned that medically actionable findings generated in the course of research should be the "floor" or minimum information offered to participants, but that "researchers might be ethically and scientifically justified in returning all genomic information (the "ceiling") in some format and any level of information in between. In this study, we found that about half of psychiatric genetics researchers interviewed believe that something more than "the floor" of medically actionable results should be offered if generated in their studies (with participants reserving the right to refuse RoR), and that results can be medically relevant or personally meaningful, even if a participant's condition cannot be treated or prevented clinically. In Kostick et al., ${ }^{10}$ we also report that these researchers have a more expansive view of "actionability" that invokes the importance of personal utility (e.g., life planning, finances, housing) and this may help explain why, as reported here, half of the researchers expressed that non-medically actionable findings, such as risk for Alzheimer disease and Huntington disease, should be offered to participants.

Researchers contextualized the emphasis on patient preferences with a corresponding need to offer specialized practices, including surrogate consent in some cases, for participants with psychiatric disorders that may affect decision-making capacity. Others pointed out that while offering individually meaningful results may be the ideal, the reality is that many results in psychiatric genetics currently lack substantive treatment applications. Notably, while the vast majority of these researchers support returning certain types of individual results, most are not returning them. ${ }^{10} \mathrm{We}$ previously reported that only $22 \%$ have returned results systematically, defined as using a consistent policy outlined in the consent form in at least one of their studies. ${ }^{10}$ The gap between the "best" versus "actual" practices also applies for follow-up and treatment, whereby researchers' preferences for providing timely and actionable results are complicated by difficulties in recontacting individuals, especially individuals who are not already receiving care. These challenges are often compounded by delays between consent and analysis of results. Further, researchers reported feeling ill-equipped to effectively route individuals into care when needed, due to a lack of guidelines for and expertise in navigating a "fragmented" health-care system lacking active collaborations between psychiatric clinicians and researchers.

Respondents thus called for greater training and guidance for how to conduct RoR and explicitly appealed to existing organizations to offer needed resources. Recently, the National Academies of Sciences, Engineering, and Medicine issued general guidelines for returning individual results in research, and more specific guidelines related to psychiatric genetics results are offered by Lázaro-Muñoz et al. ${ }^{5}$ Missing from these guidelines are the "how to" recommendations brought up by researchers in this study, including how to return findings, whether to offer results directly to research participants, who should be involved in returning results, and how to obtain necessary resources, training, and support for returning results responsibly. Additionally, researchers report needing greater clarity about how to best provide information about clinical implications and to predict or avoid negative impacts on participants who may be at risk or diagnosed with a psychiatric disorder and their families. Whether we should develop a "special" set of recommendations and processes for return of results to individuals with psychiatric disorders depends on various factors, namely the allocation of resources to make this possible while allowing this research to progress 
for the benefit of the patient population, ethical considerations, and greater evidence-based knowledge about the impacts of receiving results on participants at risk for or diagnosed with psychiatric disorders (and their relatives), including any mitigating factors. As some of us (G.L.-M.) together with the ISPG Ethics Committee have noted recently, there is a pressing need for research examining the impact of RoR on these participants. ${ }^{31}$ Little to no information is currently exchanged among researchers to help identify quality-controlled procedures to prevent or reduce harm to psychiatric participants with special needs. ${ }^{32-36}$ Significant gaps exist in the literature reporting researchers' experiences with RoR and impacts of specific RoR procedures on recipients' well-being. ${ }^{32,37-39}$

Researchers also wished to know more about who to partner with (e.g., genetic counselors, psychiatrists, institutional review boards) at which stages of research (e.g., consent versus follow-up) and how to avoid "firewalls" between research and clinical translation. While these issues are also important in other areas of genetics research, our respondents pointed out that recipients with psychiatric disorders are more likely to have special needs, including to receive results "in context" from experts who understand and may better predict how individuals with various psychiatric disorders and symptoms are likely to interpret or respond to results. This preventive approach requires greater integration of clinical and research paradigms and more research into how psychiatric genomics participants generally respond to receiving results from different sources. A growing literature likewise supports the use of genetic counselors in RoR in line with expressed preferences from our respondents, though few studies offer systematic guidelines for how and when results should be conveyed to recipients with psychiatric disorders. ${ }^{2,32}$ Further, concerns exist regarding the disproportionate need for genetic counselors relative to supply. ${ }^{40-42}$

Finally, respondents suggested that external guidelines and evidence-based norms within the field of psychiatric genetics must be supported by greater funding for RoR. One respondent poignantly observed that the lack of funding opportunities reflects an overall lack of recognition of the value of returning results responsibly to participants, as well as of mitigating the potential extra burdens RoR can place on researchers, staff, and clinicians who serve dual roles as both interpreters of genetic research results and clinical caregivers. The practical challenges of instituting these dual roles in practice have likewise been noted in other areas of genetic research ${ }^{43}$ but may be particularly acute when returning results to individuals at risk or diagnosed with a psychiatric disorder. $^{27,44}$ This is due to the potential need to identify participant characteristics (e.g., particular psychiatric states or acute episodes), in line with clinician recommendations, that may positively or negatively impact reception of results and thereby require special procedures. Over half of respondents reported concerns about available funding and noted the need for scalable strategies to meet these growing demands.

\section{Conclusion}

These findings point to significant gaps between researchers' visions for "best" versus "actual" RoR practices in psychiatric genomics. While researchers call for participant-centered practices, including consent practices that take into account special needs of participants with psychiatric disorders, return of individually meaningful results, and effective follow-up and provisions for treatment, the current reality is that consent and RoR practices lack standardized, evidence-based norms, validation, and relevance for personalized meaning and actionability. Greater interdisciplinary training, guidance, and integration of research and clinical programs are needed to improve the pursuit of best practices for RoR, along with greater quality planning, funding, and resource allocation for RoR in psychiatric genetics.

\section{SUPPLEMENTARY INFORMATION}

The online version of this article (https://doi.org/10.1038/s41436019-0642-7) contains supplementary material, which is available to authorized users.

\section{ACKNOWLEDGEMENTS}

The authors thank the researcher participants who kindly took the time to provide thoughtful responses. Research for this article was funded by the National Human Genome Research Institute (NHGRI) of the National Institutes of Health (NIH) grant R00HG008689 (G.L.-M.). The views expressed are those of the authors alone, and do not necessarily reflect views of $\mathrm{NIH}$ or Baylor College of Medicine.

\section{DISCLOSURE}

The authors declare no conflicts of interest.

Publisher's note: Springer Nature remains neutral with regard to jurisdictional claims in published maps and institutional affiliations.

\section{REFERENCES}

1. Sullivan PF, Agrawal A, Bulik CM, et al. Psychiatric genomics: an update and an agenda. Am J Psychiatry. 2017; 175:15-27.

2. Ripke S, Neale BM, Corvin A, et al. Biological insights from 108 schizophrenia-associated genetic loci. Nature. 2014;511:421

3. Sullivan PF, Daly MJ, O'donovan M. Genetic architectures of psychiatric disorders: the emerging picture and its implications. Nat Rev Genet. 2012;13:537.

4. Yuen RK, Merico D, Bookman M, et al. Whole genome sequencing resource identifies 18 new candidate genes for autism spectrum disorder. Nat Neurosci. 2017;20:602.

5. Lázaro-Muñoz G, Farrell MS, Crowley JJ, et al. Improved ethical guidance for the return of results from psychiatric genomics research. Mol Psychiatry. 2018;23:15.

6. Jarvik GP, Amendola LM, Berg JS, et al. Return of genomic results to research participants: the floor, the ceiling, and the choices in between. Am J Hum Genet. 2014;94:818-826.

7. Klitzman R, Appelbaum PS, Fyer A, et al. Researchers' views on return of incidental genomic research results: qualitative and quantitative findings. Genet Med. 2013;15:888.

8. Weiner C. Anticipate and communicate: ethical management of incidental and secondary findings in the clinical, research, and directto-consumer contexts (December 2013 report of the Presidential Commission for the Study of Bioethical Issues). Am J Epidemiol. 2014;180:562-564. 
9. Wolf SM, Crock BN, Van Ness B, et al. Managing incidental findings and research results in genomic research involving biobanks and archived data sets. Genet Med. 2012;14:361.

10. Kostick KM, Brannan C, Pereira S, Lázaro-Muñoz G. Psychiatric genetics researchers' views on offering return of results to individual participants. Am J Med Genet B Neuropsychiatr Genet. 2018 Oct 25; https://doi.org/ 10.1002/ajmg.b.32682 [Epub ahead of print].

11. Brannan C, Foulkes AL, Lázaro-Muñoz G. Preventing discrimination based on psychiatric risk biomarkers. Am J Med Genet B Neuropsychiatr Genet. 2019;180:159-171.

12. Kong $C$, Dunn M, Parker M. Psychiatric genomics and mental health treatment: setting the ethical agenda. Am J Bioeth. 2017;17:3-12.

13. Berryessa CM. Genetic essentialist biases, stigma, and lack of mitigating impact on punishment decisions. J Law Biosci. 2016:3:359-364.

14. Dar-Nimrod I, Heine SJ. Genetic essentialism: on the deceptive determinism of DNA. Psychol Bull. 2011;137:800-818.

15. Phelan JC. Geneticization of deviant behavior and consequences for stigma: the case of mental illness. J Health Soc Behav. 2005;46:307-322.

16. Bookman EB, Langehorne AA, Eckfeldt JH, et al. Reporting genetic results in research studies: summary and recommendations of an NHLBI working group. Am J Med Genet A. 2006;140:1033-1040.

17. Fabsitz RR, McGuire A, Sharp RR, et al. Ethical and practical guidelines for reporting genetic research results to study participants: updated guidelines from a National Heart, Lung, and Blood Institute working group. Circ Cardiovasc Genet. 2010;3:574-580.

18. Middleton A, Morley Kl, Bragin E, et al. Attitudes of nearly 7000 health professionals, genomic researchers and publics toward the return of incidental results from sequencing research. Eur J Hum Genet. 2016;24:21.

19. Bui ET, Anderson NK, Kassem L, McMahon FJ. Do participants in genome sequencing studies of psychiatric disorders wish to be informed of their results? A survey study. PLoS One. 2014;9:e101111.

20. Sundby A, Boolsen MW, Burgdorf KS, et al. Stakeholders in psychiatry and their attitudes toward receiving pertinent and incident findings in genomic research. Am J Med Genet A. 2017;173:2649-2658.

21. Sundby A, Boolsen MW, Burgdorf KS, et al. Attitudes of stakeholders in psychiatry towards the inclusion of children in genomic research. Hum Genomics. 2018;12:12.

22. Mathieu G, Groisman IJ, Godard B. Next generation sequencing in psychiatric research: what study participants need to know about research findings. Int J Neuropsychopharmacol. 2013;16:2119-2127.

23. Vears $D$, Sénécal $K$, Clarke $A$, et al. Points to consider for laboratories reporting results from diagnostic genomic sequencing. Eur J Hum Genet. 2018:26:36.

24. Bollinger JM, Bridges JF, Mohamed A, Kaufman D. Public preferences for the return of research results in genetic research: a conjoint analysis. Genet Med. 2014;16:932.

25. Gliwa $C$, Berkman BE. Do researchers have an obligation to actively look for genetic incidental findings? Am J Bioeth. 2013;13:32-42.

26. Kaufman D, Murphy J, Scott J, Hudson K. Subjects matter: a survey of public opinions about a large genetic cohort study. Genet Med. 2008;10:831.

27. Sundby A, Boolsen MW, Burgdorf KS, et al. The preferences of potential stakeholders in psychiatric genomic research regarding consent procedures and information delivery. Eur Psychiatry. 2019;55:29-35.

28. Saunders B, Sim J, Kingstone T, et al. Saturation in qualitative research: exploring its conceptualization and operationalization. Qual Quant. 2018;52:1893-1907.

29. Kuckartz U. Qualitative text analysis. A guide to methods, practice and using software. London: SAGE Publications; 2014.
30. Schilling J. On the pragmatics of qualitative assessment. Eur J Psychol Assess. 2006;22:28-37.

31. Lázaro-Muñoz G, Sabatello M, Huckins L, et al. International Society of Psychiatric Genetics Ethics Committee: issues facing us. Am J Med Genet B Neuropsychiatr Genet. 2019 May 23; https://doi.org/10.1002/ajmg. b.32736 [Epub ahead of print].

32. Costain G, Bassett AS. Clinical applications of schizophrenia genetics: genetic diagnosis, risk, and counseling in the molecular era. Appl Clin Genet. 2012;5:1.

33. Demkow U, Wolańczyk T. Genetic tests in major psychiatric disordersintegrating molecular medicine with clinical psychiatry-why is it so difficult? Transl Psychiatry. 2017;7:e1151.

34. Lawrence RE, Appelbaum PS. Genetic testing in psychiatry: a review of attitudes and beliefs. Psychiatry. 2011;74:315-331.

35. Lebowitz MS, Ahn W-k, Nolen-Hoeksema S. Fixable or fate? Perceptions of the biology of depression. J Consult Clin Psychol. 2013;81:518.

36. Sabatello M. Psychiatric genomic dilemmas in adolescence. Eur Neuropsychopharmacol. 2017;27:S475.

37. Austin JC, Honer WG. Psychiatric genetic counselling for parents of individuals affected with psychotic disorders: a pilot study. Early Interv Psychiatry. 2008;2:80-89.

38. Gershon ES, Alliey-Rodriguez N. New ethical issues for genetic counseling in common mental disorders. Am J Psychiatry. 2013;170:968-976.

39. Lebowitz MS, Ahn WK. Blue genes? Understanding and mitigating negative consequences of personalized information about genetic risk for depression. J Genet Couns. 2018:27:204-216.

40. Jenkins S, Arribas-Ayllon M. Genetic counselling for psychiatric disorders: accounts of psychiatric health professionals in the United Kingdom. J Genet Couns. 2016;25:1243-1255.

41. Riconda D, Grubs RE, Campion MW, Cragun D. Genetic counselor training for the next generation: where do we go from here?. Am J Med Genet C Semin Med Genet. 2018;178:38-45.

42. US Bureau of Labor Statistics. Occupational Outlook Handbook: genetic counselors. 2018. https://www.bls.gov/ooh/healthcare/ genetic-counselors.htm.

43. Bensend TA, Veach PM, Niendorf KB. What's the harm? Genetic counselor perceptions of adverse effects of genetics service provision by non-genetics professionals. J Genet Couns. 2014;23:48-63.

44. Hoge SK, Appelbaum PS. Ethics and neuropsychiatric genetics: a review of major issues. Int J Neuropsychopharmacol. 2012;15:1547-1557.

Open Access This article is licensed under a Creative Commons cc) Attribution-NonCommercial-NoDerivatives 4.0 International License, which permits any non-commercial use, sharing, distribution and reproduction in any medium or format, as long as you give appropriate credit to the original author(s) and the source, and provide a link to the Creative Commons license. You do not have permission under this license to share adapted material derived from this article or parts of it. The images or other third party material in this article are included in the article's Creative Commons license, unless indicated otherwise in a credit line to the material. If material is not included in the article's Creative Commons license and your intended use is not permitted by statutory regulation or exceeds the permitted use, you will need to obtain permission directly from the copyright holder. To view a copy of this license, visit http://creativecommons.org/licenses/by-nc-nd/4.0/.

(C) The Author(s) 2019 